\title{
Intensidade da Corrente num Condutor Electrolítico; Movimentação dos lões
}

\author{
MARIA DE SÃO PEDRO ARAG ÃO *
}

\begin{abstract}
No presente texto optou-se por simplificar propositadamente o mecanismo da movimentação de iões, uma vez que a resolução do problema proposto se destina a alunos do ensino secundário; contudo esta simplificação não altera a conclusão a que se pretende chegar.
\end{abstract}

Na sequência da publicação do artigo de V. Lobo "A passagem da corrente eléctrica num condutor electrolítico: esclarecimento de um conceito erroneamente interpretado em alguns círculos do ensino secundário" (Química, 52, 41, 1994), é minha intenção, usando uma argumentação diferente da daquele autor, confirmar que a resolução do problema: “Qual o valor médio da intensidade da corrente num condutor electrolítico em que, no intervalo de tempo de $4,0 \mathrm{~s}$, através de uma seç̧ão intermediária do seu interior, se movimentam num sentido 6,0 C de carga positiva e no sentido contrário $6,0 \mathrm{C}$ de carga negativa?" [1] não tem a resposta $\mathrm{I}=3,0 \mathrm{~A}$, mas sim a solução:

$I_{m}=\Delta Q_{+} / \Delta t=6,0 \mathrm{C} / 4,0 \mathrm{~s}=1,5 \mathrm{~A}$

ou

$\mathrm{I}_{\mathrm{m}}=\Delta \mathrm{Q}-/ \Delta \mathrm{t}=6,0 \mathrm{C} / 4,0 \mathrm{~s}=1,5 \mathrm{~A}$

\section{1 - CONSIDERAÇÕES PRELIMINARES}

Embora se trate de um manual escolar extremamente bem estruturado, logo após a saída da primeira edição datada de 1977 [1], manifestei a um dos autores a minha discordância relativamente à resolução do problema acima enunciado.

Creio que a fundamentação sustentada é a seguinte: como a intensidade de corrente tem igual valor em todo o circuito isso significa que terá de ser igual a carga total que atravessa qualquer secção recta do circuito, num determinado intervalo de tempo. Este pressuposto implica que, se num intervalo de tempo de 4,0 segundos qualquer secção recta de um fio metálico é atravessada por uma carga electrónica de 6,0 C, também 6,0 C de electrões são captados junto ao cátodo por 6,0 C transportados por iões positivos da solução e $6,0 \mathrm{C}$ de electrōes são transferidos para o ânodo por 6,0 C transportados por iões negativos da solução, enquanto que, nesse mesmo intervalo de tempo, no interior do condutor electrolítico se cruzam em qualquer secção uma carga iónica absoluta total de 6,0 C (sendo eventualmente na secção média de 3,0 C num sentido e 3,0 $\mathrm{C}$ no sentido inverso). Deste modo, seria encontrado para a intensidade de corrente o mesmo valor em qualquer secção do circuito (do fio metálico, ou encostada aos eléctrodos ou no interior do condutor electrolítico) dado por $\mathrm{I}=6,0 / 4,0=1,5 \mathrm{~A}$.

No entanto , a opinião de que, em cada secção do interior do voltâmetro, a soma das cargas absolutas que passam nos dois sentidos é também de 6,0 C não me parece poder ser sustentada por um mecanismo de movimentação dos iões através do condutor electrolítico, como adiante procurarei mostrar.

O caso de um condutor electrolítico em que há uma corrente real de um tipo de carga num sentido e outra corrente real de carga de sinal contrário em sentido oposto, implica um tratamento distinto do de um condutor metálico em que há movimento real de um só tipo de carga num único sentido. Admitindo que a movimentação de um tipo de carga num sentido também pode ser interpretada como uma deslocação de carga de sinal contrário em sentido oposto (sabemos que a corrente de electrões num fio metálico é equivalente a uma corrente virtual de carga positiva em sentido oposto), então no interior de uma célula electrolítica cada uma das duas correntes reais de iões é equivalente a uma corrente virtual de carga de sinal contrário em sentido oposto. Deste modo, em meu entender, durante o processo electrolítico existem duas correntes, uma de iões positivos e outra de iões negativos, ambas de igual intensidade cada uma com a mesma intensidade que a da corrente de electrões nos fios metálicos - independentes entre si e não adicionáveis, em que a intensidade de qualquer delas representa a intensidade da corrente eléctrica no voltâmetro.

Em relação aos exemplos apresentados por V. Lobo, este autor não se questionou sobre se a carga positiva e a carga negativa em movimento são ou não iguais em diferentes secções do voltâmetro e para intervalos de tempo suficientemente longos. Em boa verdade, para tirar conclusões quanto à intensidade da corrente eléctrica, tal não é necessário: é-o, porém, para refutar o ponto de vista dos autores do manual escolar. Considero, todavia, que V. Lobo resumiu bem a questão subjacente ao assunto que estamos a tratar quando afirma "Num condutor electrolítico há movimentação de cargas positivas num sentido e negativas no outro. A intensidade da corrente será a soma das cargas positivas com as cargas negativas que passam por unidade de tempo ou, será sim, a carga que passa num só sentido por unidade de tempo? Por outras palavras, a carga

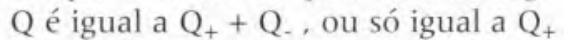
ou a Q.?" Ressalvando que a igualdade $Q_{+}=Q$. é válida para o conjunto do voltâmetro, mas nem sempre aplicável por secções, e utilisando o raciocínio de $\mathrm{V}$. Lobo, resumirei a questão a resolver: no interior do condutor electrolítico o valor da intensidade de corrente, I, deve ser calculado pelo quociente entre a carga $\Delta Q$ de um determinado sinal que atravessa uma dada secção num intervalo de tempo $\Delta t$, isto é $I=\Delta Q_{+} / \Delta t$ ou $I=/ \Delta Q . / / \Delta t$, no que apoio $V$. Lobo, ou o valor de I é calculado a partir da soma dos valores absolutos dos dois tipos de carga que atravessam uma seç̧ão do interior do voltâmetro de acordo com $I=\left(\Delta Q_{+}+/ \Delta Q_{-} /\right) / \Delta t$, como é advogado no manual escolar.

As leis da electrólise nada nos informam sobre esta dúvida dicotómica: de facto, as Leis de Faraday regem apenas os depósitos electrolíticos originados nas reacções de eléctrodo, nāo elucidando sobre o comportamento das cargas em secções do interior do voltâmetro. Por este mo- 
tivo procurarei em seguida tratar a questão através de um esquema de movimentação de iões, primeiro para uma fase primordial da electrólise em que a solução electrolítica é sensivelmente homogénea, depois, atendendo à migração dos iões no decorrer do tempo em que a assimetria dos dois tipos de carga por secção se vai acentuando.

\section{2 - MECANISMO \\ DA MOVIMENTAÇÃO DE IÕES NUM CONDUTOR ELECTROLÍTICO}

Escolha-se, como exemplo, a electrólise de uma solução aquosa de cloreto de cobre(II), a qual será tratada como uma electrólise primária, conduzindo à deposição de cobre metálico no eléctrodo negativo $\mathrm{E}_{1}$ (cátodo) e à libertação de cloro gasoso junto ao eléctrodo positivo $\mathrm{E}_{2}$ (ânodo) [2] (figura 1).

Admita-se que a célula electrolítica tem uma forma paralelipipédica e os eléctrodos $E_{1}$ e $E_{2}$ são placas de carbono (grafite) encostadas a duas faces opostas e com as dimensões destas, de modo que a movimentação ordenada de iões se processe, apenas, no volume compreendido entre os eléctrodos, onde se estabelece um campo eléctrico uniforme $\overrightarrow{\mathrm{E}}$. No início do processo electrolítico (figura 1), considere-se para o efeito um número

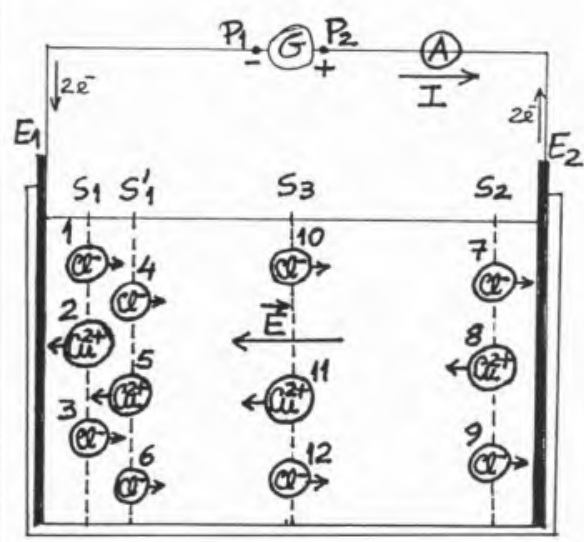

Fig. 1 - Representação esquemática da fase primordial do processo electrolítico do cloreto de cobre (II) reduzido de iões, que se numeram para facilidade de localização, deslocando-se através de algumas superfícies imaginárias de líquido, $\mathrm{S}_{1}, \mathrm{~S}_{1}, \mathrm{~S}_{2}$ e $\mathrm{S}_{3}$, paralelas aos eléctrodos.

Supunhamos a secção $S_{1}$ tão próxima do eléctrodo $\mathrm{E}_{1}$ que o ião 2 de $\mathrm{Cu}^{2+}$, após atravessá-la, atinge $\mathrm{E}_{1}$ e aí capta dois electrões, dando origem a um átomo de cobre metálico. Nesse mesmo intervalo de tempo, dois iões negativos de $\mathrm{Cl}^{-}$, repelidos por $E_{1}$, o 1 e o 3, deverão atravessar $\mathrm{S}_{1}$ em sentido inverso, repondo assim a neutralidade eléctrica na superfície $\mathrm{S}_{1}$. Entretanto a superfície $\mathrm{S}_{1}{ }_{1}$, próxima de $\mathrm{S}_{1}$, deverá ser atravessada pelos iões 4,5 e 6 , nos sentidos indicados na figura. Após estes movimentos manter-se-á a neutralidade eléctrica na região intercalar entre $S_{1}$ e $S_{1}^{*}$, na qual entraram os iōes 1 e 3 de $\mathrm{Cl}^{-}$e o ião 5 de $\mathrm{Cu}^{2+}$.

Vejamos agora o que, no mesmo intervalo de tempo, se está a passar junto do eléctrodo positivo $\mathrm{E}_{2}$. Estando a secção $S_{2}$ suficientemente próxima de $E_{2}$ podemos considerar que os dois iões cloreto 7 e 9, após terem-na atravessado, atingem o eléctrodo positivo e nele depositam dois electões, originando dois átomos de cloro que se ligam formando uma molécula de cloro gasoso. Entretanto o ião 8 de $\mathrm{Cu}^{2+}$, actuado por uma força eléctrica em sentido contrário, atravessará $\mathrm{S}_{2}$ afastando-se do eléctrodo positivo.

Atendendo à resistência oferecida pela solução electrolítica à movimentação dos iões, a electroneutralidade em cada secção do líquido deve ser conseguida pelo deslocamento de iões que se encontram na sua vizinhança; será, portanto, extremamente improvável que a neutralidade eléctrica seja reposta em qualquer superfície por iões relativamente afastados. Imaginando então secções sucessivamente próximas, facilmente antevemos o movimento progressivo de cargas eléctricas positivas e negativas ocorrido nesse intervalo de tempo, quer junto aos eléctrodos quer em regiões afastadas destes.

Nestas condições a secção média, $\mathrm{S}_{3}$, do interior do condutor electrolítico, será atravessada pelo ião 11 de $\mathrm{Cu}^{2+}$ no sentido dos potenciais decrescentes e pelos iões 10 e $12 \mathrm{de}^{*}$ no sentido dos potenciais crescentes (figura 1), por acção da força eléctrica $(\vec{F}=q \vec{E})$ a que cada ião está submetido.

Debrucemo-nos, agora, sobre o mecanismo necessário à continuidade da corrente eléctrica entre a solução e a parte sólida do circuito.

Constatamos que, nesse mesmo intervalo de tempo elementar, provenientes do fio de ligação entre o polo $\mathrm{P}_{1}$ do gerador e o eléctrodo negativo $\mathrm{E}_{1}$, atingem o cátodo dois electrões que são captados pelo ião 2 de $\mathrm{Cu}^{2+}$ e simultâneamente serão libertados no eléctrodo positivo $\mathrm{E}_{2}$, dois electrões fornecidos pelos iões 7 e 9 de $\mathrm{Cl}^{-}$, que transitarão para o fio de ligação entre o ânodo e o pólo positivo $\mathrm{P}_{2}$ do gerador.

Portanto, na fase primordial do processo electrolítico, em qualquer secção do condutor electrolítico, próxima ou afastada dos eléctrodos, haverá movimento, em sentidos opostos, de ambos os tipos de iões, dada a homogeneidade inicial da solução.

$\mathrm{O}$ esquema exposto pressupõe ainda que a resistência oferecida à passagem dos iões permite uma velocidade constante para a sua movimentação: só assim seria possível todas as secções imaginárias serem, num dado intervalo de tempo, atravessadas pelo mesmo número de iões do mesmo tipo. No início, no interior do voltâmetro, a tendência é para a manutenção da electroneutralidade nas diferentes seç̧ōes.

Podemos então concluir que, numa fase primordial da electrólise (atendendo à carga absoluta do electrão de $1,6 \times 10^{-19} \mathrm{C}$ ), para um dado intervalo de tempo $\Delta \mathrm{t}$, quando uma qualquer secção recta de um fio de ligação é atravessada por uma carga negativa $\left|\Delta \mathrm{Q}_{-}\right|=2 \mathrm{n} \times 1,6 \times 10^{-19} \mathrm{C}$, qualquer secção imaginária do condutor electrolítico (do seu interior ou juntos aos eléctrodos) é atravessada no sentido do ânodo para o cátodo por uma carga positiva $\Delta \mathrm{Q}_{+}=\mathrm{n} \times 2 \times$ $1,6 \times 10^{-19} \mathrm{C}$ (transportada por $\mathrm{n}$ iōes $\mathrm{Cu}^{2+}$ ) e em sentido contrário por uma carga negativa $|\Delta \mathrm{Q}|=.2 \mathrm{n} x$ 
1,6 $\times 10^{-19} \mathrm{C}$ (transportada por $2 \mathrm{n}$ iões $\mathrm{Cl}^{-}$). Como vemos, a intensidade da corrente nos fios de ligação é, portanto, apenas igual à intensidade de uma das correntes de iões no interior da célula electrolítica (ou pela corrente de iões positivos ou pela corrente de iões negativos). Isto é, se num intervalo de tempo de $4,0 \mathrm{~s}$ uma secção intermédia do condutor electrolítico for atravessada por 6,0 C de carga positiva num sentido e por 6,0 C de carga negativa em sentido oposto, junto a cada um dos eléctrodos reagirão 6,0 C de carga.

Não vejo, pois, como aceitar que a carga que atinge e reage em cada um dos eléctrodos seja igual à soma da carga positiva e da carga negativa que atravessa uma qualquer secção recta do interior do voltâmetro. Nem mesmo com o avançar da electrólise tal se torna aceitável, como adiante se verá.

\section{3 - MIGRAC ÃO DOS IÕES NO CONDUTOR ELECTROLÍTICO}

À medida que o processo electrolítico progride os iões $\mathrm{Cl}^{-}$serão repelidos das proximidades do cátodo e constituirão uma corrente dirigida para o ânodo $E_{2}$, assim como os iões $\mathrm{Cu}^{2+}$ serão afastados de $\mathrm{E}_{2}$ e ir-se-ão aproximando de $E_{1}$. Embora sendo iguais os totais de carga positiva e negativa presentes no voltâmetro, haverá uma distribuição assimétrica e a neutralidade eléctrica já não se verificará em superfícies próximas dos eléctrodos.

Por outro lado, à medida que a electrólise avança, vai diminuindo o número de iões positivos e negativos do condutor electrolítico (por passagem a átomos). É de esperar que o número de iões que reage, por unidade de tempo, junto dos eléctrodos, varie no tempo, alterando-se a intensidade de corrente eléctrica, muito em particular na fase terminal da electrólise.

Igualmente as reaç̧ões secundárias que ocorrem na célula electrolítica conduzirão a alterações de $\mathrm{pH}$ do meio e da constituição dos eléctrodos, assim como do tipo, número e distri- buição dos iões, ao longo do tempo, afectando o valor da intensidade de corrente. Todas estas condicionantes dificultam o estabelecimento de um mecanismo para a deslocação dos iões em função do tempo.

No decorrer da electrólise cada ião está sujeito a uma força eléctrica que deveria tornar acelerado o seu movimento. Admitiremos a hipótese de a resistência oferecida pela solução ao deslocamento dos iões permitir uma velocidade de migração sensivelmente constante. Para facilidade de exposição não distinguiremos entre o valor médio da velocidade dos catiões e a dos aniões, não nos preocuparemos com o facto de que nem todos os iões do mesmo sinal possuem, num determinado instante, o mesmo valor de velocidade e nem atenderemos às variações de velocidade no tempo para um dado ião. Também não entraremos em linha de conta com os fenómenos secundários que ocorrem no interior do voltâmetro. As limitações introduzidas, porém, não restringem, como se verá, o carácter geral da conclusão que se procura.

Ilustremos o processo através de um exemplo numérico. Seja uma célula electrolítica cúbica com $10 \mathrm{~cm}$ de aresta, cujos eléctrodos são placas quadradas encostadas a faces paralelas, contendo uma solução aquosa $1,0 \times 10^{-3} \mathrm{M}$ de $\mathrm{CuCl}_{2}$. Antes do início da electrólise, no volume de $1,0 \mathrm{dm}^{3}$ encontram-se $1,0 \times 10^{-3} \times 6,0 \times 10^{23}$ iões $\mathrm{Cu}^{2+}$ e $2,0 \times 10^{-3} \times 6,0 \times 10^{23}$ iões $\mathrm{Cl}^{-}$; a carga correspondente será:

$$
\mathrm{Q}_{\mathrm{Cu}}{ }^{2+}=6,0 \times 10^{20} \times 2 \times 1,6 \times 10^{-19}=6 \times 32 \mathrm{C}
$$

$\mathrm{Q}_{\mathrm{CI}^{-}}=2 \times 6,0 \times 10^{20} \times\left(-1,6 \times 10^{-19}\right)=6 \times(-32) \mathrm{C}$

Suponhamos que em cada $320 \mathrm{~s}$ atravessam uma secção recta dos fios

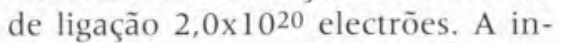
tensidade de corrente no circuito será:

$$
\begin{gathered}
\mathrm{I}=\left|\Delta \mathrm{Q}_{-}\right| / \Delta \mathrm{t}=2,0 \times 10^{20} \times 1,6 \times 10^{-19} \mid \\
320=32 \mathrm{C} / 320 \mathrm{~s}=0,10 \mathrm{~A} \\
\text { Então, em cada intervalo de } \\
\text { tempo de } 320 \mathrm{~s} \text {, atingirão o cátodo } \\
2,0 \times 10^{20} \text { electrões que serão capta- } \\
\text { dos por } 1,0 \times 10^{20} \text { iões } \mathrm{Cu}^{2+} \text {, dando }
\end{gathered}
$$

origem à deposição de $1,0 \times 10^{20}$ átomos de cobre metálico. Simultaneamente no ânodo serão libertados $2,0 \times 10^{20}$ iões $\mathrm{Cl}^{-}$, os quais passando a átomos e ligando-se entre si origi-

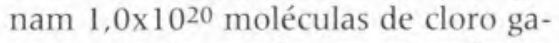
soso. Deste modo, mantendo-se constante a intensidade da corrente, em cada 320 s reagem junto a cada um dos eléctrodos $32 \mathrm{C}$ transportados por iões de carga de sinal oposto. Como as cargas totais positiva e negativa contidas inicialmente na célula electrolítica são cada uma de $6 \mathrm{x}$ $32 \mathrm{C}$, se a intensidade da corrente se mantivesse constante até ao final, de acordo com o quadro de hipóteses extremamente simplista que se admitiu, a electrólise da solução mencionada processar-se-ia em 6 x 320 s.

Imaginemos, então, o que se passaria em 6 volumes iguais no interior do voltâmetro, durante 6 intervalos de tempo consecutivos de $320 \mathrm{~s}$.

No início da electrólise cada um dos 6 volumes conterá $1,0 \times 10^{20}$ iões $\mathrm{Cu}^{2+}$ e 2,0x1020 iões $\mathrm{Cl}^{-}$(figura 2.1). Durante os primeiros $320 \mathrm{~s}$, haverá $1,0 \times 10^{20}$ iões $\mathrm{Cu}^{2+}$ que se depositam sob a forma de cobre metálico no eléctrodo negativo; podemos supor que foram os iões $\mathrm{Cu}^{2+}$ inicialmente contidos no volume 1 que sairam da solução passando a átomos. Para que no intervalo de tempo seguinte de $320 \mathrm{~s}$, voltem a depositar-se $1,0 \times 10^{20}$

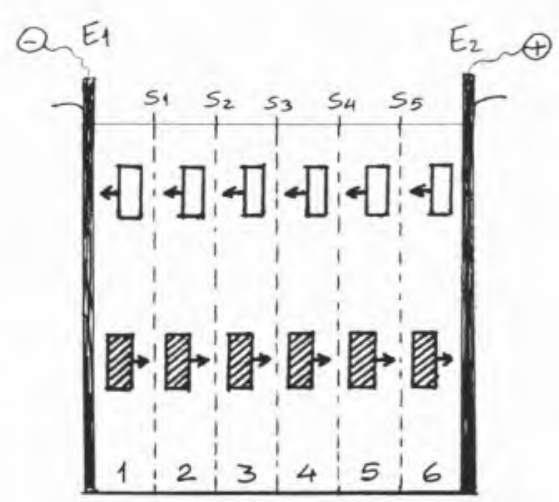

representa $1,0 \times 10^{20}$ iões $\mathrm{Cu}^{2+}$ representa $2,0 \times 10^{21}$

Fig. 2.1 - Representação esquemática inicial da célula electrolitica. 
átomos de cobre metálico em $\mathrm{E}_{1}$, é preciso que nos primeiros $320 \mathrm{~s}$ os iões $\mathrm{Cu}^{2+}$ contidos no volume 2 tenham transitado para o volume 1 , atravessando a secção $S_{1}$. Será então de esperar que, nos primeiros $320 \mathrm{~s}$, cada uma das secções imaginárias $S_{1}$, $\mathrm{S}_{2}, \mathrm{~S}_{3}, \mathrm{~S}_{4}$ e $\mathrm{S}_{5}$ tenha sido atravessada, no sentido dos potenciais decrescentes, por $1,0 \times 10^{20}$ iões de $\mathrm{Cu}^{2+}$, ou seja por $32 \mathrm{C}$ de carga positiva.

Um raciocínio análogo permite concluir que, nos primeiros $320 \mathrm{~s}$, os iões $\mathrm{Cl}^{-}$contidos no volume 6 saíram da solução dando origem a moléculas de cloro gasoso e concomitantemente cada uma das secções, de $S_{1}, a S_{5}$, foi atravessada, no sentido dos potenciais crescentes, por $2,0 \times 10^{20}$ iões $\mathrm{Cl}^{\circ}$, ou seja por $32 \mathrm{C}$ de carga negativa.

Em resumo, nos primeiros 320 s, cada secção é, portanto, atravessada por $32 \mathrm{C}$ de carga positiva num sentido e por $32 \mathrm{C}$ de carga negativa no sentido oposto. Por outras palavras, enquanto $32 \mathrm{C}$ de carga positiva reagem no eléctrodo negativo e a mesma quantidade de carga reage no eléctrodo positivo, uma seç̧ão no interior do voltâmetro será atravessada por $64 \mathrm{C}$ de carga, em valor absoluto.

A intensidade de corrente no interior do condutor electrolítico será calculada por:

$$
\begin{aligned}
\mathrm{I} & =\left|\Delta \mathrm{Q}_{+}\right| / \Delta \mathrm{t}=\left|\Delta \mathrm{Q}_{-}\right| / \Delta \mathrm{t} \\
& =32 \mathrm{C} / 320 \mathrm{~s}=0,10 \mathrm{~A}
\end{aligned}
$$

para que a intensidade de corrente no interior do voltâmetro seja igual à intensidade de corrente nos fios de ligação.

Vejamos agora o novo posicionamento dos iões passado o primeiro intervalo de tempo de 320 s (figura 2.2). Os iões $\mathrm{Cu}^{2+}$ já só estarão situados nos volumes 1, 2, 3, 4 e 5 e os iões $\mathrm{Cl}^{-}$nos volumes 2, 3, 4, 5 e 6 . Durante o segundo intervalo de tempo de $320 \mathrm{~s}$ a superfície $\mathrm{S}_{1}$ será atravessada apenas por $32 \mathrm{C}$ de carga transportada por iões $\mathrm{Cu}^{2+}$, que a cruzam passando do volume 2 para o volume 1 (enquanto os iões $\mathrm{Cu}^{2+}$ contidos no volume 1 reagem no cátodo) e a secção $S_{5}$ já não será atravessada por iões $\mathrm{Cu}^{2+}$. A secção $\mathrm{S}_{5}$
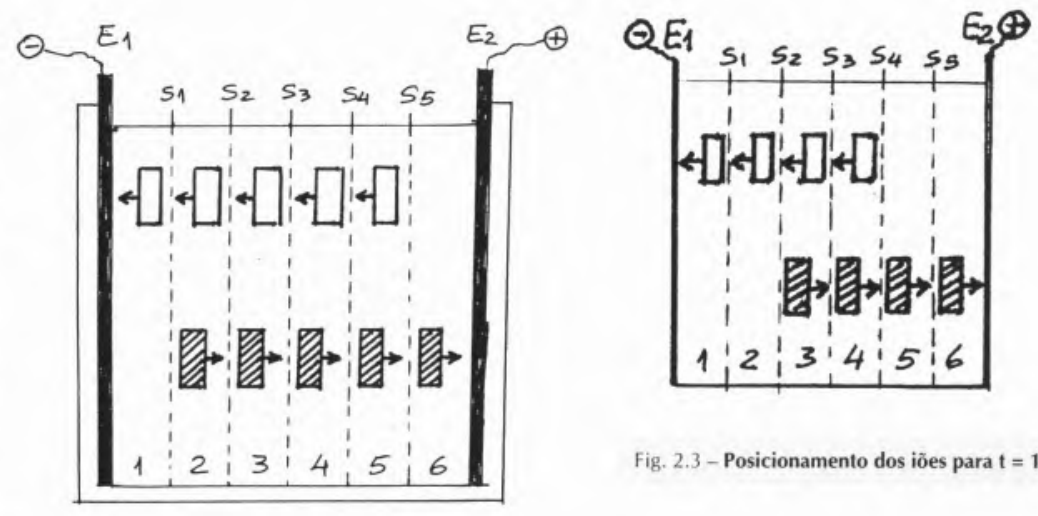

Fig. 2.3 - Posicionamento dos iões para $\mathrm{t}=1 \times 320 \mathrm{~s}$.

Fig. 2.2 - Representação esquemática

do posicionamento dos iões pelos 6 volumes parcelares, passados os primeiros $320 \mathrm{~s}$.

será cruzada apenas por $32 \mathrm{C}$ transportados por iões $\mathrm{Cl}^{-}$e a superfície $\mathrm{S}_{1}$ já não será atravessada por iões $\mathrm{Cl}^{-}$. As figuras 2.3, 2.4, 2.5 e 2.6 ilustram o posicionamento dos iões por intervalos de tempo sucessivos de $320 \mathrm{~s}$, representando cada rectângulo branco $1,0 \times 10^{20}$ iões $\mathrm{Cu}^{2+}$ e cada rectângulo a tracejado $2,0 \times 10^{20}$ iões $\mathrm{Cl}^{-}$.

O conjunto dos esquemas expostos, traduzindo uma progressão do movimento de iões no tempo desde a fase primordial até quase à fase final da electrólise, embora extremamente simplificativos e redutores (nomeadamente supondo uma velocidade de arrastamento constante no tempo e igual para todos os iões) permitem pôr em evidência importantes aspectos de um qualquer processo electrolítico.

- Exceptuando a fase inicial da electrólise, as diferentes secções do interior do voltâmetro não são necessariamente atravessadas por igual valor de carga eléctrica e, além disso, o valor da carga que atravessa uma dada secção não é constante no tempo.

- A partir de certa altura as várias secções do voltâmetro são já, praticamente, atravessadas por um só tipo de iões, acentuando-se até ao final a assimetria na distribuição da carga pelo fenómeno da migração dos iões dentro da célula electrolítica. A partir de um certo instante já nem é verdade que todas as secções sejam atravessadas por carga eléctrica.

- Fundamentalmente este estudo seccionado por volumes põe em

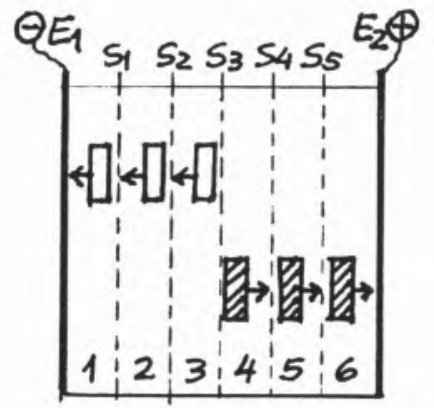

Fig. 2.4 - Posicionamento dos iões para $\mathrm{t}=3 \times 320 \mathrm{~s}$.

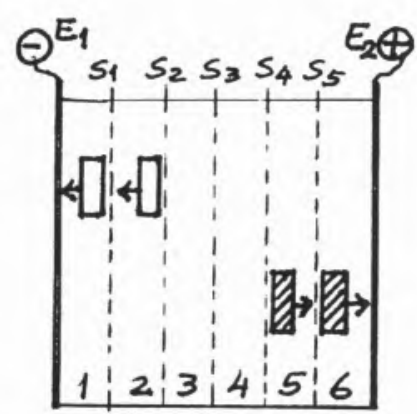

Fig. 2.5 - Posicionamento dos iões para $\mathrm{t}=4 \times 320$ s.

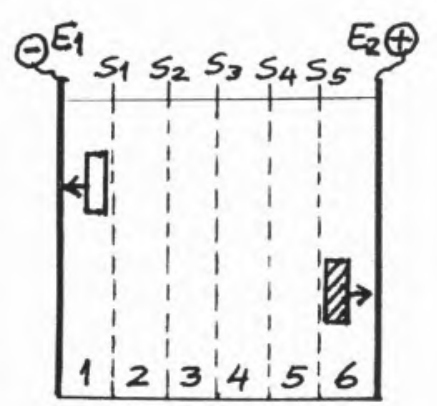

Fig. 2.6 - Posicionamento dos ióes para $\mathrm{t}=5 \times 320 \mathrm{~s}$. 
destaque que até ao fim são detectados movimentos orientados de iões, constituindo duas correntes eléctricas, uma de carga negativa, no sentido dos potenciais crescentes, e outra de carga positiva no sentido dos potenciais decrescentes, conduzindo a que em cada eléctrodo reajam iguais quantidades de carga eléctrica. Esta constatação leva-nos a compreender o conteúdo das leis de Faraday da electrólise, segundo o qual a massa de um elemento produzido numa reacção de eléctrodo catódica ou anódica, é directamente proporcional à intensidade de corrente no circuito e ao intervalo de tempo durante a qual se dá a passagem desta, sendo a massa de elemento libertada independente da forma e dimensões do voltâmetro [3].

\section{4 - INTENSIDADE \\ DA CORRENTE ELÉCTRICA}

Do anteriormente exposto pode-se confirmar que num condutor electrolítico existem duas corren- tes, uma de iões positivos e outra de iões negativos, ambas de igual intensidade - cada uma com a mesma intensidade que a da corrente de electrões nos fios metálicos - e a intensidade de qualquer delas representando a intensidade da corrente eléctrica dentro do voltâmetro. Deste modo o problema referido no início desta opinião, em que uma superfície imaginária é atravessada, num intervalo de tempo de $4,0 \mathrm{~s}$, por uma carga $\Delta Q_{+}$de 6,0 C num sentido e uma carga $\Delta Q$. em sentido inverso, só pode ter a seguinte solução:

$\mathrm{I}_{\mathrm{m}}=\Delta \mathrm{Q}_{+} / \Delta \mathrm{t}=\left|\Delta \mathrm{Q}_{\mathrm{.}}\right| / \Delta \mathrm{t}=6,0 \mathrm{C} / 4,0 \mathrm{~s}=1,5 \mathrm{~A}$

Em conclusão. sendo consensual o facto de que a intensidade de corrente deve ser expressa pelo mesmo valor em qualquer porção do circuito, a única solução compatível com o raciocínio que desenvolvemos é a de que, no interior do condutor electrolítico, a intensidade média de corrente deve ser dada indiferentemente por:

$$
\mathrm{I}_{\mathrm{m}}=\Delta \mathrm{Q}_{+} / \Delta \mathrm{t} \text { ou } \mathrm{I}_{\mathrm{m}}=|\Delta \mathrm{Q} \cdot| / \Delta \mathrm{t}
$$

Trata-se, afinal, tão só, de respeitar a definição de intensidade de corrente num condutor: "Se for $\Delta \mathrm{Q}$ a carga que atravessa, em determinado sentido, uma secção recta do circuito, durante um intervalo de tempo $\Delta \mathrm{t}$, define-se intensidade média da corrente, $I_{m}$, pela relação $I_{m}=\Delta \mathrm{Q} / \Delta \mathrm{t}^{\prime \prime}[4]$.

* Escola Secundária Pedro Nunes, Av. Álvares Cabral, 1250 Lisboa

REFERÊNCIAS E NOTAS

1. A. Aido, M. A. P. Ponte, M. A. Martins, M. G. A. Bastos, M. I. Pereira, M. M. Leitão, R. Carvalho, Física - para o $2^{\circ}$ Ano do Curso Complementar do Ensino Secundário, Livraria Sá da Costa Editora, Lisboa, 1977, p. 134, ou ediçào de 1984, p. 76. Na formulaçâo do problema foram alterados os valores da carga, obtendo-se como solução a resposta dada no manual.

2. Não se tomou em consideraçăo a libertação simultânea de oxigénio devido à reacção de oxidação no ânodo: $2 \mathrm{H}_{2} \mathrm{O}$ $\rightarrow \mathrm{O}_{2}+4 \mathrm{H}^{+}+4 \mathrm{e}^{-}$

3.1. Teixeira, Curso de Física - $3^{\circ}$ ciclo Liceal $-7^{\circ}$ ano, Coimbra Editora, Coimbra, 1966, p. 230.

4. Livro citado em [1], p. 133, ou na edição de 1984, p. 75

\section{Cromatógrafo Gasoso Modelo 4890A \\ da Nossa Representada "Hewlett-Packard"}

\section{Novo Cromatografo Gasoso desenvolvido especialmente para análises de rotina e para o ensino.}

Equipamento de alta qualidade, para utilização "single chanel" (uma coluna e um detector) que oferece uma excelente "performance" química a um preço muito atractivo. Para mais informações, consulte a nossa Direcção Comercial.

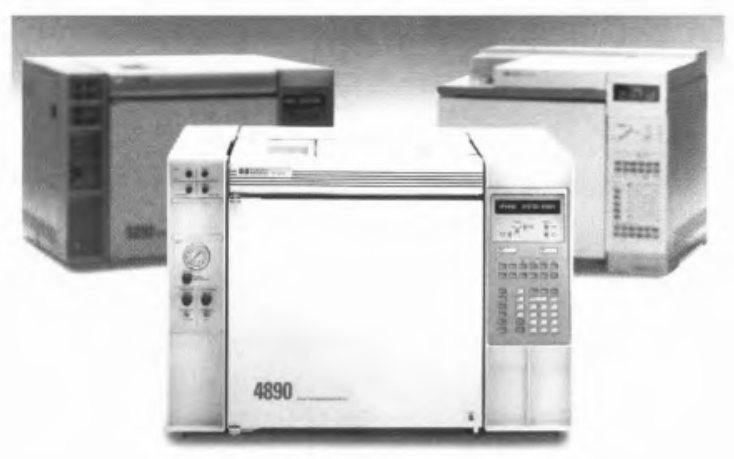

\section{Sociedade de Representações e Química, Lda.}

Rua Coronel Santos Pedroso, 15 • 1500 LISBOA • Tel.: 7165160 • Fax: 7165169 Sede Social: Av. da Liberdade, 220-2 $2^{\circ} 129$ LISBOA CODEX 